\title{
The Happy Xylophone: Acoustics Affordances Restrict An Emotional Palate
}

\author{
MICHAEL SCHUTZ[1] \\ Longwood University \\ DAVID HURON \\ Ohio State University \\ KRISTOPHER KEETON \\ Virginia Commonwealth University \\ GREG LOEWER \\ Virginia Commonwealth University
}

\begin{abstract}
In many ways, the structure of music resembles that of language, including the acoustic cues used to communicate emotion. In speech, sadness is imparted through a combination of low fundamental frequency, dark timbre, and a slow rate of articulation. As the acoustic properties of the xylophone are not conducive to mimicking these cues, it seems to follow that composers would avoid attempts to write "sad" music for it. We investigated this idea by comparing the repertoire of the xylophone with that of the marimba - a similar instrument whose acoustic structure permits a greater variety of timbres, pitch heights, and tone durations. An analysis of repertoire drawn from the Percussive Arts Society database of recital programs reveals that $60 \%$ of the tonal marimba examples surveyed were written in minor (nominally "sad") keys. In contrast, a parallel analysis of xylophone literature found minor keys used in only $6 \%$ of the examples surveyed. Further investigation revealed that the only examples of minor-key xylophone compositions included in this survey are in fact typically performed on the marimba. The avoidance of minor-key works on xylophone by both composers and performers is consistent with the idea that instruments restricted to producing tones with short durations, bright timbres, and high pitch heights are unable to mimic the speech cues used to convey sadness and/or depression.
\end{abstract}

Submitted 2008 April 13; accepted 2008 August 16.

KEYWORDS: music, speech prosody, emotion, modality, xylophone

AS both music and language are human universals (Nettl, 2000) sharing deep structural similarities (Lerdahl \& Jackendoff, 1983), parallels between the two are abundant. The neural processing of speech and music exhibit a great deal of overlap (Koelsch, Kasper, Sammler, Schulze, Gunter, \& Friederici, 2004; Maess, Koelsch, Gunter \& Friederici, 2001; Patel, Gibson, Ratner, Besson \& Holcomb, 1998), and there is evidence suggesting the basis for tonal music can be found in the spectral content of spoken utterances (Schwartz, Howe, \& Purves, 2003; Ross, Choi \& Purves, 2007). Rhythmic patterns in music often resemble those used in speech, such that a composer's native language can influence his or her choices of rhythmic patterns even when composing instrumental (e.g., non-vocal) music (Patel \& Daniele, 2003; Huron \& Ollen, 2003). Given that the connection between the two domains extends into techniques for communicating emotion (Juslin \& Laukka, 2003; Gabrielsson \& Juslin, 2003), we are interested in how the acoustic restrictions of the xylophone (a tuned, wooden bar-percussion instrument) affect the emotional tone of its repertoire.

Sadness in speech is signaled largely through the use of lower fundamental frequency (F0), decreased amounts of high-frequency energy, and slower articulation rates (Scherer, 2003). The musical parallels of these cues are pitch height, timbre, and note-articulation rate. Modern xylophones exhibit a 
relatively high pitch range [2], bright timbre (Beck, 1995), and short note durations (Peters, 1995) making slow articulation rates impractical. Therefore, it appears that the acoustic properties of the xylophone are ill-suited for mimicking the cues used in speech to signal a sad affect. If so, we would expect composers to shy away from attempts to create sad xylophone music. This notion was tested by comparing the repertoire of the xylophone to that of its closest acoustic cousin - the marimba (another tuned, wooden bar-percussion instrument). Although in many ways similar, the marimba relative to the xylophone exhibits a wider pitch range, more variation in timbre, and longer note durations (Peters, 1995), allowing for the possibility of employing a greater range of articulation rates. As it differs from the xylophone primarily in allowing more variability among the acoustic dimensions of interest; a survey of its repertoire serves as an ideal point of reference for interpreting that of the more acoustically restricted xylophone.

In order to quantitatively index the emotional tone of a large number of compositions, an independent method is needed to judge affective content. For Western-enculturated listeners, modality (major versus minor) has long been associated with the portrayal or evoking of particular emotions: the major mode is commonly linked to happy or joyful emotions whereas the minor mode is linked to sad, lethargic, or serious emotions (Hevner, 1935). Though factors such as tempo and/or articulation rate also play a role, modality is the primary dimension predicting ratings of affect (Dalla Bella, Peretz, Rousseau, Gosselin, 2001). Therefore while modality may provide only a rough estimate of a composer's affective intentions, it serves as a sufficient operational index for the purposes of testing our hypothesis.

Consequently, we examined the starting and ending keys of a representative sample of standard marimba and xylophone works. Our results indicate a clear avoidance of minor-keys in the xylophone repertoire, consistent with the idea that its acoustic affordances are not well suited to the evoking or portrayal of a sad affect. Moreover, further investigation will suggest that composers' efforts to challenge the stereotype of the "happy xylophone" have been met with resistance on the part of performers, who seem to avoid performing minor key pieces on the xylophone even when this is explicitly requested by composers.

\section{METHOD}

\section{Repertoire}

Testing our hypothesis required access to the notated music for a variety of marimba and xylophone compositions. While a library of musical scores might provide an appropriate sample, the presence or absence of individual scores gives little information concerning a work's relative popularity. A more representative sample might be obtained by surveying the repertoire regularly performed in recitals. An online database of recent recital programs maintained by the Percussive Arts Society (PAS) served as a starting point for these efforts. The following multi-stage criteria were used to select approximately 50 commonly performed pieces in the marimba and xylophone repertoire.

\section{SELECTION OF RECITAL PROGRAMS}

In order for a composition to be included in the survey, it must appear on an eligible concert program as determined by the following criteria:

1) Program must be from a 2007 recital, and appear in the PAS database as of August 12th, 2007. Given the time consuming nature of locating and analyzing each composition, this relatively narrow time window was chosen as a matter of convenience. Although a more extensive sample from a larger time-frame would in some ways have been preferable, the strength of our findings makes it unlikely that a larger sample would alter our conclusions.

2) Recitals must be at the undergraduate, graduate, faculty or professional level.

3) In order to avoid over-representation from a single institution and in order to keep the sample size manageable, only one program was chosen from each institution.

4) When multiple recitals were listed at a single institution, we selected the first program that included a xylophone solo. As the database contained many more performances of marimba solos [3], this restraint was adopted to maximize the number of xylophone pieces included in the survey. In cases where no xylophone solo was performed at a given institution, we chose the first listed program. 


\section{SELECTION OF COMPOSITIONS}

From the 46 eligible programs, individual compositions were selected based on the following criteria:

1) Composition must appear on at least one of the eligible recital programs.

2) Composition must appear on at least 5 programs within the entire PAS database (i.e. any year).

3) Composition must be a solo (or solo with accompaniment), rather than a chamber work.

4) An intended performing instrument of either xylophone or marimba must be clearly stated. Percussionists are fond of performing literature written for other instruments (e.g. guitar, violin, cello, etc). Because the database does not list performing instrument, it was difficult to determine on which a transcription was played. However, those transcriptions popular enough to warrant formal publication of a new edition clearly stating instrument preference were included.

These criteria yielded 49 of the most commonly performed solo works (13 xylophone, 36 marimba) written by 31 composers. In order to reflect changes in modality between movements, each movement was assessed independently resulting in a total of 16 xylophone and 60 marimba examples.

\section{Modality Determination}

A comprehensive measure-by-measure analysis of the modality for each of the 76 examples was deemed impractical. Since it is not unreasonable to assume the opening and closing modalities are reflective of overall tendencies, we decided a priori to examine samples drawn from the beginning and ending of each example (152 total samples). Modality was determined by looking for agreement among the written key signature, accidentals implying tonal areas (e.g. raised sevenths functioning as leading tones for minor keys), harmonic progressions suggestive of specific tonal centers, and clear cadences. This process proved straight-forward for all xylophone samples, which exhibited strong converging evidence amongst the selection criteria. The marimba samples proved more complex, owing in part to the prevalence of atonal literature in its repertoire. Accordingly, while Figure 1 graphs the modalities for samples drawn from the beginning and ending of all 60 marimba examples, the statistical analysis was based only on samples from the 36 marimba examples displaying clear information regarding mode at both sample points. A complete list of composers, compositions, and modality identification is included in Appendix B.

\section{RESULTS AND ANALYSIS}

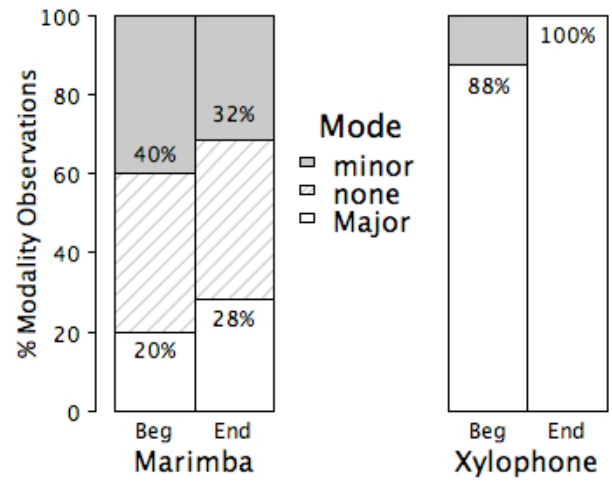

Fig. 1. Proportion of major and minor modes for sampled marimba and xylophone repertoires. Results are graphed separately for beginnings and endings of each example, with thatched regions identifying those lacking a clear modality. Numbers in grey boxes indicate the percentage of minor-key samples, white boxes the percentage of major-key samples. The results suggest an avoidance of minor keys in the repertoire of the xylophone relative to that of the marimba. 
Ignoring examples lacking clear modalities, a chi-square statistic on one degree of freedom examining the number of major instances observed in the 32 xylophone samples (16 beginnings and 16 endings), using expected values from the 72 marimba samples (36 beginnings and 36 endings) found significantly more instances of major modes $(1, \mathrm{~N}=32)=38.042(\mathrm{p}<.0005)$ in the xylophone repertoire. This result (shown graphically in Figure 1) is consistent with the idea that the acoustic affordances of the xylophone are not well suited for portraying or evoking a sad affect.

The 72 composition-movements in this survey exhibiting clear modality information were taken from 49 unique compositions written by only 23 unique composers. Therefore, it could be argued that the popularity of a few prolific composers calls into question the assumption of data independence required for using a chi-square analysis. While our survey by definition favors only those composers favored by performers themselves, for the sake of caution we re-ran our analysis on two subsets of the survey, 1) using only the first movement of multi-movement works (as well as single movement compositions), and 2) using only a single example from each composer. As detailed in Appendix A, the results of both of these approaches agreed with those reported above, showing a clear avoidance of minor keys in the xylophone repertoire.

\section{DISCUSSION}

Our analysis of representative samples of the marimba and xylophone literature was consistent with the notion that composers avoid writing sad music for the xylophone. Its bright timbre, high pitch-range, and short duration (likely prompting composers to write more notes-per-second) essentially stack the deck against its ability to effectively communicate sadness. While any one of these individual factors might account for this limitation, prior research shows that emotional character is best conveyed when many cues act simultaneously (House, 1990). Essentially, the acoustic structure of the xylophone has type-cast it as a happy instrument.

Further experimental work is needed to isolate the independent contributions of timbre, pitch height, and note duration. However, this survey represents an initial step, demonstrating that the musical intuitions of composers and performers appear to have shaped the musical canon in a manner consistent with research on speech prosody. The results of this study suggest that similar surveys might be profitably carried out with other pairs of related instruments such as the harpsichord and piano, banjo and guitar, etc. Indeed, it is likely acoustic limitations similar to those of the xylophone which prompted the comedian Steve Martin (also an accomplished musician) to remark that "it is not possible to play sad music on the banjo." (2007)

As with any study of this nature, our criteria are not perfect. While the PAS listing of programs serves as the most authoritative database publicly available, its completeness is dictated by those who choose to submit programs (which are done voluntarily by individual performers). However, the list of pieces included in our analysis reads like a standard repertoire list - 35 of the 49 selected compositions have been performed and/or taught by one of the two authors who teach applied percussion at accredited universities. It is worth noting that "ragtime" tunes are popular selections for xylophone features on recitals. As they are overwhelmingly in major keys and ragtime music forms the core of the xylophone canon, it could be said that this biases our survey in favor of major-key xylophone solos. However, by basing our literature survey on actual recital programs from 2007, we ensured that our sample favored only those compositions favored by percussionists themselves. Furthermore, this tendency for performers (and audiences) to prefer a particular style of music on the xylophone suggests there may be something inherently fitting about this genre-instrument combination. Finally, while in principle it would be entirely possible to perform any of these ragtime xylophone compositions on the marimba, to the best of our knowledge this is rarely done. However, the same cannot be said for the two examples of minor-key xylophone works encountered in this survey.

Regarded as a significant western composition exhibiting non-western influence (Kostka, 2006), Alan Hovhaness's Fantasy on Japanese Footprints represents an effort to introduce minor-key literature to the xylophone [4]. Listed 55 times in the database, it appears quite successful in this attempt given the average of 55.3 performances [5] for all xylophone examples. Yet it is common knowledge among percussionists that this is frequently performed on the marimba, rather than the xylophone. This intuition was verified by emailing the seven performers (or teachers when students were unreachable) listed as performing Fantasy since an arbitrary cutoff date of January $1^{\text {st }}, 2000$. The results were even more striking than the modality analysis itself. 
Four of the seven contacted percussionists responded, with all four indicating the relevant performance was given on marimba (note: the score clearly states the piece should be performed on xylophone). When asked why, comments ranged from a general "I personally don't like the sound of this piece on xylophone," to more specific comments such as, "the marimba allows more connection and sustain." One even suggested using the marimba for slow portions but reverting to the xylophone for the fast sections! Similar preferences were observed with Thomas Pitfield's Sonata for Xylophone. It appears twice in the database since the January $1^{\text {st }} 2000$ cutoff date, and ironically enough both performances of Sonata for Xylophone were in fact given on the marimba. The reasons offered by the contacted performers echo those mentioned for Hovhaness's Fantasy. "I've always thought this piece sounded better on marimba . . . in fact, I can't ever remember hearing a performance on the xylophone! I wish I had something more profound to tell you, but it's that simple." Ultimately, the strongest evidence that the acoustic affordances of the xylophone render it ill-suited for sad music come from the general refusal of performers to use it for minor key compositions, even when this contradicts the stated wishes of the composer.

\section{CONCLUSION}

In this study, we have shown a bias against minor-mode compositions for xylophone. The inspiration for our hypothesis arose from the observation that its acoustic affordances are inconsistent with three prosodic cues known to characterize sad speech - namely dark timbre, low pitch height, and slow articulation rate. From our survey of popular recital pieces, we conclude that composers implicitly acknowledge this shortcoming by avoiding minor keys when composing for the xylophone. Consequently, major keys dominate its repertoire - after accounting for actual performance practice, major keys were used in $100 \%$ of the 22 xylophone examples (11 beginnings and 11 endings) included in this survey. Given that the few attempts to introduce minor key literature into the repertoire for xylophone have been met by performers with outright defiance, we believe efforts to challenge the xylophone's status as an inherently happy instrument are unlikely to gain acceptance as its acoustic affordances are inconsistent with the acoustic cues used to convey sadness.

\section{NOTES}

[1] Please address all correspondence to Michael Schutz at schutz@ alumni.northwestern.edu.

[2] While the ranges of these keyboard percussion instruments are not standardized, the concert marimba, which commonly spans 5 octaves (C2-C7), has a range which is both larger and lower than the concert xylophone, commonly spanning 3.5 octaves (F4-C8).

[3] Perhaps in part as its longer duration has led to more "serious" pieces

[4] Due to the non-western influence, classification of modality is somewhat ambiguous. However the introduction leans more strongly to minor than major, and is clearer modally than the marimba examples classified as "non-tonal." As the performances tracked in this survey were given within the United States, it is not unreasonable to assume this work "sounded minor" to western-enculturated audiences.

[5] The selection criteria were designed to pick the most popular works in each repertoire. Therefore it is reasonable to use the grand average of performances amongst these pieces as a benchmark for measuring wide-spread acceptance of works for each instrument. Note: Though popular enough to meet our selection criteria, two xylophone pieces are currently unpublished and were not counted when calculating the average number of performances.

\section{REFERENCES}

Beck, John (1995). Encyclopedia of Percussion. Routledge: New York City, NY, pp. 367. 
Dalla Bella, S., Peretz, I., Rousseau, L., \& Gosselin, N. (2001). A developmental study of the affective value of tempo and mode in music. Cognition, Vol. 80, Issue 3, pp. B1-B10.

Gabrielsson, A. and Juslin, P. (2003) Emotional Expression in Music. In: H.H. Goldsmith, R.J. Davidson and K.R. Scherer (Eds.), Handbook of Affective Sciences. New York: Oxford University Press, pp. 503534.

Hevner, K. (1937). The affective value of pitch and tempo in music. American Journal of Psychology, Vol. 49, No. 4, pp. 621-630.

House, David. (1990). Tonal perception in speech. PhD dissertation, Lund University, Sweden.

Huron, D., \& Ollen, J. (2003). Agogic contrast in French and English themes: Further support for Patel and Daniele (2003). Music Perception, Vol. 21, pp. 267-271.

Juslin, P. N., \& Laukka, P. (2003). Communication of emotions in vocal expression and music performance: Different channels, same code? Psychological Bulletin, Vol. 129, pp. 770-814.

Koelsch, S., Kasper, E., Sammler, D., Schulze, K., Gunter, T., \& Friederici, A. D. (2004). Music, language and meaning: Brain signatures of semantic processing. Nature Neuroscience, Vol. 7, No. 3, pp. 302-307.

Kostka, S. (2006). Materials and Techniques of Twentieth-Century Music. $3^{\text {rd }}$ edition. Upper Saddle River, New Jersey: Pearson Prentice Hall, pp. 171.

Lerdahl, F., \& Jackendoff, R. (1983). A Generative Theory of Tonal Music. Cambridge, MA: MIT Press, pp. $314-330$

Maess, B., Koelsch, S., Gunter, T. C., \& Friederici, A. (2001). Musical syntax is processed in Broca's area: an meg study. Nature Neuroscience, Vol. 4, No. 5, pp. 540-545.

Nettl, B. (2000). An ethnomusicologist contemplates universals in musical sound and musical culture. In N. L. Wallin, B. Merker \& S. Brown (Eds), The origins of music (pp. 463-72). Cambridge, Massachusetts: MIT Press.

Patel, A. \& Daniele, J. (2003). An empirical comparison of rhythm in language and music music. Cognition, Vol. 87, No. 1, pp. B35-B45.

Patel, A, Gibson, E., Ratner, J., Besson, M., \& Holcomb, P. (1998). Processing syntactic relations in language and music: An event-related potential study. Journal of Cognitive Neuroscience, Vol. 10, pp. 717-733.

Peters, M. (1995). Fundamental Method for Mallets - Book 1. Van Nuys, California: Alfred Publishing, pp. 8-9.

Ross, D., Choi, J., \& Purves, D. (2007). Musical intervals in speech. Proceedings of the National Academy of Sciences, Vol. 14, No. 23, pp. 9852-9857.

Scherer, K. (2003). Vocal communication of emotion: A review of research paradigms. Speech Communication, Vol. 40, Issues 1-2, pp. 227-256.

Schwartz, D., Howe, C., \& Purves, D. (2003). The statistical structure of human speech sounds predicts musical universals. Journal of Neuroscience, Vol. 23, No. 18, pp. 7160-7168. 


\section{APPENDICIES}

\section{Appendix A - Additional Analyses}

To alleviate any concerns related to statistical independence given that 23 unique individuals composed the 72 examples (composition-movements) drawn from the 49 compositions included in our survey, we re-ran the analysis on two subsets of the original data.

1) Unique composition-examples: We eliminated all but the first movement from multi-movement works. This restriction removed 15 marimba and 3 xylophone examples, leaving a survey based on 34 unique compositions (21 marimba, 13 xylophone).

2) Unique composer \& composition-examples: For composers still appearing multiple times, we discarded all works other than the first (determined by alphabetic order of title). This restriction eliminated an additional 4 marimba and 7 xylophone compositions, leaving a survey based on unique compositionexamples from 23 unique composers (17 marimba, 6 xylophone).

Analysis of these two subsets led to similar conclusions. There were still significantly more instances of major modalities in the xylophone repertoire after eliminating redundancy in composition-examples $(1, \mathrm{~N}=$ $26)=36.563(\mathrm{p}<.0005)$ and composers $(1, \mathrm{~N}=12)=12.343(\mathrm{p}<.0005)$. As shown in Table 1 , the percentage of major key pieces for each instrument, as well as the ratio of major key pieces between instruments varied little as a result of these further restrictions.

Table. 1. Percentage of major key examples for the xylophone and marimba, as well as the ratio of major key percentages between these two instruments. Data from the original survey appear on line one, data restricted to the using only the first movement of multi-movement works on line two, and data further restricted to include only a single composition per-composer on line three. All three surveys produced similar results.

\begin{tabular}{lcccl}
\hline & $\begin{array}{c}\text { \% Major } \\
\text { Xylophone }\end{array}$ & $\begin{array}{c}\text { \% Major } \\
\text { Marimba }\end{array}$ & $\begin{array}{c}\text { Major-key ratio } \\
\text { (xylo/marimba) }\end{array}$ & $\begin{array}{l}\text { Examples surveyed } \\
\text { Total (marimba, xylo) }\end{array}$ \\
\hline All examples & 94 & 40 & 2.328 & $49(36,16)$ \\
$\begin{array}{l}\text { Only first movements } \\
\begin{array}{l}\text { Only first movements of } \\
\text { unique composers }\end{array}\end{array}$ & 96 & 40 & 2.376 & $34(21,13)$ \\
\hline
\end{tabular}




\section{Appendix B - Repertoire}

Complete list of 16 xylophone (Figure 2) and 60 marimba (Figure 3) examples, drawn from the 36 marimba and 13 xylophone compositions included in this survey. Samples classified as modally ambiguous, unclear, and/or atonal are indicated by "undet."

Table. 2. Xylophone repertoire analyzed. Each movement from multi-movement works was treated separately, with the beginning and ending tonal areas classified as either Major or minor (all xylophone examples had clearly defined tonal areas).

\begin{tabular}{llll}
\hline Composer & Composition (movement) & Begins & Ends \\
& & & \\
\hline Becker, Bob & Bye Bye Medley & Major & Major \\
Becker, Bob & Girlfriends Medley & Major & Major \\
Breuer, Harry & Back Talk & Major & Major \\
Green, George H & Chromatic Fox Trot & Major & Major \\
Green, George H & Cross Corners & Major & Major \\
Green, George H & Jovial Jasper & Major & Major \\
Green, George H & Log Cabin Blues & Major & Major \\
Green, George H & The Whistler & Major & Major \\
Green, George H & Valse Brilliant & Major & Major \\
Green, George H & Xylophonia & Major & Major \\
Hovhaness, Alan & Fantasy on Japanese Woodprints & minor & Major \\
Kreisler, Fritz & Tambourin Chinois & Major & Major \\
Pitfield, Thomas & Sonata for xylophone (I) & Major & Major \\
Pitfield, Thomas & Sonata for xylophone (II) & Major & Major \\
Pitfield, Thomas & Sonata for xylophone (III) & Major & Major \\
Pitfield, Thomas & Sonata for xylophone (IV) & minor & Major \\
\hline
\end{tabular}


Table. 3. Marimba repertoire included in the analysis. Each movement from multi-movement works was treated separately, with the beginning and ending tonal areas classified as either Major, minor, or undetermined.

\begin{tabular}{|c|c|c|c|}
\hline Composer & Composition (movement) & Begins & Ends \\
\hline Abe, Keiko & Dream of the Cherry Blossoms & minor & minor \\
\hline Abe, Keiko & Variations on Japanese Children Songs & undet & undet \\
\hline Burritt, Michael & Caritas (I) & minor & Major \\
\hline Burritt, Michael & Caritas (II) & minor & minor \\
\hline Burritt, Michael & Caritas (III) & minor & minor \\
\hline Burritt, Michael & October Night (I) & Major & Major \\
\hline Burritt, Michael & October Night (II) & undet & Major \\
\hline Burritt, Michael & The Offering & undet & Major \\
\hline Creston, Paul & Concertino for Marimba and Orchestra (I) & minor & minor \\
\hline Creston, Paul & Concertino for Marimba and Orchestra (II) & minor & Major \\
\hline Creston, Paul & Concertino for Marimba and Orchestra (III) & Major & Major \\
\hline Deane, Christopher & Etude for a Quite Hall & minor & Major \\
\hline Druckman, Jacob & Reflections on the Nature of Water (I) & undet & undet \\
\hline Druckman, Jacob & Reflections on the Nature of Water (II) & undet & undet \\
\hline Druckman, Jacob & Reflections on the Nature of Water (III) & undet & undet \\
\hline Druckman, Jacob & Reflections on the Nature of Water (IV) & undet & undet \\
\hline Druckman, Jacob & Reflections on the Nature of Water (V) & undet & undet \\
\hline Edwards, Ross & Marimba Danses (I) & Major & Major \\
\hline Edwards, Ross & Marimba Danses (II) & minor & minor \\
\hline Edwards, Ross & Marimba Danses (III) & Major & Major \\
\hline Ewazen, Eric & Northern Lights & minor & Major \\
\hline Fissinger, Alfred & Suite for Marimba (I) & minor & minor \\
\hline Fissinger, Alfred & Suite for Marimba (II) & minor & minor \\
\hline Fissinger, Alfred & Suite for Marimba (III) & minor & Major \\
\hline Fissinger, Alfred & Suite for Marimba (IV) & Major & Major \\
\hline Ford, Mark & Polaris & undet & undet \\
\hline Gipson, Richard & Monography IV & minor & minor \\
\hline Glennie, Evelyn & A Little Prayer & Major & Major \\
\hline Maslanka, David & My Lady White (I) & minor & Major \\
\hline Maslanka, David & My Lady White (II) & minor & minor \\
\hline Maslanka, David & My Lady White (III) & minor & minor \\
\hline Maslanka, David & Variations on Lost Love (I) & minor & minor \\
\hline Maslanka, David & Variations on Lost Love (II) & minor & minor \\
\hline Maslanka, David & Variations on Lost Love (III) & undet & Major \\
\hline Miki, Minoru & Marimba Spiritual & undet & undet \\
\hline Miki, Minoru & Time & undet & undet \\
\hline Muramatsu, Takatsugu & Land & Major & Major \\
\hline Musser, Clair & Etude, Op 6, no 8 & Major & Major \\
\hline O'Meara, Rich & Tune for Mary $\mathrm{O}$ & Major & minor \\
\hline
\end{tabular}




\begin{tabular}{llll}
\hline Rosauro, Ney & Concerto for Marimba and Orchestra (I) & minor & minor \\
Rosauro, Ney & Concerto for Marimba and Orchestra (II) & minor & minor \\
Rosauro, Ney & Concerto for Marimba and Orchestra (III) & Major & Major \\
Rosauro, Ney & Concerto for Marimba and Orchestra (IV) & undet & minor \\
Sammut, Eric & Rotation No. 4 & undet & Major \\
Schwantner, Joseph & Velocities & undet & undet \\
Smadbeck, Paul & Rhythm Song & minor & minor \\
Smadbeck, Paul & Virginia Tate & minor & undet \\
Stout, Gordon & Astral Dance & minor & minor \\
Stout, Gordon & Etude No. 1 & undet & undet \\
Stout, Gordon & Etude No. 2 & minor & minor \\
Stout, Gordon & Reverie & undet & undet \\
Stout, Gordon & Rumble Strips & undet & undet \\
Stout, Gordon & Two Mexican dances (Mvt I) & Major & Major \\
Stout, Gordon & Two Mexican dances (Mvt II) & Major & Major \\
Tanaka, Toshimitsu & Two Movements for Marimba I & undet & undet \\
Tanaka, Toshimitsu & Two Movements for Marimba II & undet & undet \\
Thomas, Andrew & Merlin (I) & undet & undet \\
Thomas, Andrew & Merlin (II) & undet & undet \\
Zivkovic, Nebojsa & Illijas & minor & minor \\
Zivkovic, Nebojsa & Ultimatum I & undet & undet \\
\hline
\end{tabular}

